https://doi.org/10.48009/1_iis_2007_65-70

\title{
TRANSNATIONAL HIGHER EDUCATION: \\ ISSUES EFFECTING JOINT DEGREE PROGRAMS AMONG US AND CHINESE SCHOOLS
}

\author{
Wenying “Nan” Sun, Washburn University, nan.sun@washburn.edu \\ Robert J. Boncella, Washburn University, bob.boncella@washburn.edu
}

\begin{abstract}
Globalization leads to the need for transnational education. Transnational joint degree programs are a realization of transnational higher education. Joint degree programs between US and Chinese universities are rare. Our university is exploring opportunities with Chinese universities to develop joint degree programs. This paper argues that joint programs are appealing but implementation is not without difficulties. To illustrate these difficulties we map a US Computer Science and Technology curriculum to three Chinese curricula to identify major gaps between curricula in the two countries. We then propose solutions to address the curricula gaps.
\end{abstract}

Keywords: transnational education, joint degree programs, globalization, US/China joint degrees

\section{BACKGROUND}

\section{From Globalization to Transnational Higher Education}

"Globalization is a process of interaction and integration among the people, companies, and governments of different nations, a process driven by international trade and investment and aided by information technology" [3]. The drivers of globalization are knowledge based information and innovation based on that information. As a result, globalization will have an effect on the perceived competency of a nation's higher education system.

If a nation's higher education system does not yield knowledge based information for innovation, that system will be perceived as lacking the ability to graduate students that can compete globally. In order to resolve this deficit a nation may turn to transnational higher education as a solution. Transnational Education denotes any teaching or learning activity in which the students are in a different country (the host country) than that in which the institution providing the education is based (the home country). Transnational Joint Degree Programs are a realization of Transnational Higher Education where a student is provided the opportunity to earn a "joint degree."
In the United States a de facto joint degree would be one where a two year institution of higher education, a junior college or community college, has an articulation agreement with a four year school of higher education. The agreement specifies that if a student pursues a specific course of study at the two year school and if the student then pursues an associated course of study at the four year school, the student will be awarded a degree of the four year school. Transnational joint degree programs could take a similar approach.

One definition of a transnational joint degree is: "an arrangement whereby providers in different countries collaborate to offer a program for which a student receives a qualification from each provider or a joint award from the collaborating providers. It is a degree which is cosponsored with other institutions" [2].

The Lisbon/ UNESCO /CoE-definition of a joint degree is:

"A joint degree should be understood as referring to a higher education qualification issued jointly by at least two or more higher education institutions or jointly by one or more higher education institutions and other awarding bodies, on the basis of a study program developed and/or provided jointly by the higher education institutions, possibly also in cooperation with other institutions. A joint degree may be issued as

- A joint diploma in addition to one or more national diplomas

- A joint diploma issued by the institutions offering the study program in question without being accompanied by any national diploma,

- one or more national diplomas issued officially as the only attestation of joint qualification in question" [10].

In general, a transnational higher education joint program can be in the form of an "X + Y program" where a student studies in country $A$ for $X$ years and then resides in another country $\mathrm{B}$ to study for $\mathrm{Y}$ years. At the end the student receives the degree diploma from one university. 


\section{Why Establish Transnational Joint Degree Programs with China?}

One author succinctly states the advantages for China. "The state expects transnational joint programs to help improve the quality of China's human resources, upgrade China's educational system, meet the national educational demand, prevent brain drain, and attract foreign capital into education" [14]. The cost to the state would be less to send students to study abroad for "Y years" than build the required academic infrastructure to meet these expectations in country.

For small and medium size US schools, transnational joint degree programs would increase enrollment and hold the possibility for a "differential tuition" premium. A potential market for medium size schools would be in the area of Information Systems Management. Larger US schools would also benefit in this way but, more importantly, for a research school it would be an increase in the number of potential graduate students already familiar with the culture. Furthermore, for the US, this type of program would improve cultural exchange and lead to increased understanding of our nation's interdependency. In the area of business transnational degree programs would foster cooperative competition, "coopetition," among US and Chinese firms.

Establishing transnational joint degree programs with China brings many benefits for both countries. However, creating such a joint degree is not a simple matter. It contains a number of issues not faced when one creates an articulation agreement among higher education institutions in the US. We illustrate the major issues with an example.

\section{AN EXAMPLE}

In order to identify the curriculum issues between universities in the two countries, we compared curricula at our school and those of three Chinese universities. We used the technique of juxtaposition described below. Also described is our method of data collection. The result of this method data collection is a table that represents mappings that identify some major issues. Even though the specific curriculum presented is Computer Science and Technology (CS\&T), the same issues were found in other programs such as Business Administration or a Bachelor of Science in Nursing.

\section{Method of Comparison and Evaluation}

The curricula are evaluated and compared by using the technique of juxtaposition [1]. The data to be evaluated and compared are juxtaposed with each other for the purpose of matching similar data items. Tabular (vertical) juxtaposition are used for curricula evaluation and text (horizontal) juxtaposition are used for comparison.

\section{Method of Data Collection}

The information about Chinese curricula was acquired during a May 2005 visit to the specific universities. Subsequent phone conversations and email resulted in additional information about Chinese CS\&T curricula. The majorities of the cited references are written in Chinese and are so noted in the references. As a result, the information presented is a translation making it accessible to wider readership.

Information regarding a US curriculum was collected in a similar manner. In this instance the authors were in part responsible for the CS\&T curriculum.

The table below shows the US degree requirements in five categories: university requirement, general education requirement, correlated courses, major courses, and major electives. For each requirement, check boxes are available: a check in the box indicates there are matching courses in terms of title and description at the corresponding Chinese school, and a blank means the lack of matching classes.

\begin{tabular}{|c|c|c|c|}
\hline US [11] & $\begin{array}{l}\text { Ch1[7 } \\
\text { ] }\end{array}$ & $\begin{array}{l}\text { Ch2[9 } \\
]\end{array}$ & $\begin{array}{l}\text { Ch3[1 } \\
\text { 3] }\end{array}$ \\
\hline \multicolumn{4}{|c|}{ University Requirement (9) } \\
\hline $\begin{array}{l}\text { Junior \& Senior English } \\
\text { Composition }\end{array}$ & 凶 & 凶 & 凶 \\
\hline Physical Education & Х & 区 & Х \\
\hline College Math & $\bigotimes$ & $\bigotimes$ & $\bigotimes$ \\
\hline \multicolumn{4}{|c|}{ General Education Requirement (27) } \\
\hline Humanities & $\square$ & $\square$ & $\square$ \\
\hline Natural Science & $\bigotimes$ & $\bigotimes$ & $\bigotimes$ \\
\hline Social Science & $\square$ & $\square$ & $\square$ \\
\hline \multicolumn{4}{|c|}{ Correlated (42) } \\
\hline Logic & $\square$ & $\square$ & $\square$ \\
\hline Business & $\square$ & $\triangle 1$ & $\square$ \\
\hline
\end{tabular}




\begin{tabular}{|c|c|c|c|}
\hline Communication & $\square$ & $\triangle 2$ & $\square$ \\
\hline Math & $\bigotimes$ & 凶 & $\bigotimes$ \\
\hline \multicolumn{4}{|c|}{ Major Required (34) } \\
\hline programming & 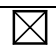 & $\bigotimes$ & 凶 \\
\hline Computer organization & Х & 凶 & Х \\
\hline Networking & Х & Х & Х \\
\hline Data structure & 凶 & $\bigotimes$ & $\bigotimes$ \\
\hline Operating Systems & 邓 & Х & 邓 \\
\hline Software Engineering & 区 & 区 & 邓 \\
\hline Database & 凶 & 凶 & 凶 \\
\hline $\begin{array}{l}\text { Computational } \\
\text { Intelligence }\end{array}$ & $\square$ & $\square$ & $\square$ \\
\hline Capstone & Х & 凶 & Х \\
\hline ACP Exam & $\square$ & $\square$ & $\square$ \\
\hline \multicolumn{4}{|c|}{ Major Electives (12) } \\
\hline Variety of Courses & 凶 & 凶 & 凶 \\
\hline
\end{tabular}

Note $1 \& 2$ - Could be fulfilled by taking electives.

Several findings are derived through the mapping process. First, there is a significant amount of agreement in courses between the US and Chinese curricula. Out of the 124 hours required by the US degree in CS\&T, about half of the hours can be fulfilled by the Chinese curriculum requirements. Second, the Chinese curricula are very similar in what they cover and do not cover. For instance, all Chinese schools are heavy on natural science and major courses, but none of them require humanities and social sciences. Third, significant gaps/issues exist. Based on reviews of other degree programs, those issues do not surround one particular program but actually occur across the board. Five major issues were identified and explained below.

\section{ISSUES}

Issue 1 - The two countries share drastically different views of the purpose of college education and what general education serves in higher education. The Chinese education system believes that the purpose of college education is to provide students skills in a particular subject area and assumes that general education in humanities and social sciences are completed before college. Each Chinese college student is mandated to take certain courses, but the selection of those courses is done by the Chinese Ministry of Education, and the courses cover political theories the central government wants every student to study. The US education system sees that "the essential core of an undergraduate education is to establish the foundations for living a productive life, to be a citizen of the world, to appreciate aesthetic values, and to engage in life-long learning in a continually changing world. For this reason, the general education requirements provide for breadth across the humanities and arts, social studies, biological sciences and physical sciences" [12]. Specializing in a subject matter in a US degree is a major component but by no means the sole purpose.

Issue 2 - Correlated courses presents a challenge. Correlated courses are viewed by China as a minor extension of the specialty area. A Chinese science degree in CS\&T typically requires correlated courses only in the natural sciences. The US uses correlated courses to broaden the students' intellectual horizons by covering different subjects. An US science degree in CS\&T not only requires courses in natural science but also provides students opportunities to acquire fundamental human skills such as public speaking and interpersonal communication. The students in Ch1 do have the chance to fulfill the business and communication requirements. It is done through electives. Thus, unless students are extremely careful at picking electives, the correlated courses remain an issue between US and Chinese curricula.

Issue 3 - A major motivation for Chinese students to come to the US is to improve their English language skills. This entails that even though the Chinese students take a substantial number of English classes in China, up to four in some cases, they still need to take additional English courses in a US institute to boost their language skills. That implies additional language courses should be a required component in the joint program, which will increase the total number of hours required to graduate.

Issue 4 - Some minor gaps in the major courses are inevitable. In the case of CS\&T, the gap lies on computational intelligence and certification exam. None of the Chinese schools have these two requirements.

Issue 5 - For courses that have the same title and description, what factors are used for comparison to determine equivalency? It is unlikely the content description is sufficient. Hence, we need to consider other factors such as teaching materials, delivery method, faculty qualification, etc. If a course is found not to be equivalent, how is this resolved? 


\section{Models to address the issues}

Several models of joint programs are alternatives to address the various issues identified in the previous section. The different models are: (1) Chinese degree only, (2) US degree with $100 \%$ US requirements, (3) US degree with focus on major only, and (4) US degree with combination of US and Chinese requirements.

In model 1 - Chinese degree only, the Chinese students receive diplomas from their home institution upon graduation. The Chinese institution has total control of its curriculum content. The majority of the curriculum content is delivered by Chinese professors while their US counterparts provide some pre-defined major courses in English using American textbooks that cover topics in which the US has a lot more expertise. The Chinese students can apply for a short term study (6 month -1 year) in the US institution to take the courses, but if the visa or travel expense becomes an issue, those courses are offered by the US professors on Chinese campus.

In this model, since the US institution only offers a limited number of major courses, and the degree the student receives is a Chinese degree, the curriculum issues that arise from the differences in curriculum design become irrelevant. The Chinese institution follows its own requirements while at the same time ensures that its students have the language and subject foundation skills to absorb the US courses efficiently.

This model is appealing in several ways. First, it solves all the curriculum issues without any curriculum changes. Second, failing to obtain visa does not jeopardize learning opportunities. Third, it cuts down cost for the Chinese students. However, there are two main drawbacks in this model: first, students may not get the opportunity to be exposed to the cultural, linguistic, and technological environment on the US campus; secondly, the degree is a Chinese degree which may limit its market value to certain regions. The joint program in Automobile Electrical Engineering between Lawrence Technological University (LTU) and Shanghai Institute of Engineering and Technology (SIET) follows this model [8]. Eight major courses are taught by professors at LTU: Vehicle Engineering Principles, Engineering Materials, Engineering Cost Analysis, Engineering Quality Control, Digital Signal Processing, Electrical Machines and Controls, Automotive Electronics, and Automotive Applications of Microcontrollers. SIET handles all other requirements. Upon graduation, qualified students are awarded with the Bachelor's degree in engineering from SIET.

In model 2 - US degree with 100\% US requirements, the Chinese students spend minimum time in their home institution taking preparatory courses so they can come to the US to fulfill all US requirements in order to receive a US degree. The Chinese institution needs to find out how it can prepare students to be successful in a US degree program. The main advantage in this approach is that it solves all the curriculum issues without any change in the US curriculum content. Furthermore, the US institution enjoys increased enrollment while conducting courses as usual. The main disadvantage is that the role of the Chinese institution is so diminished that the Chinese institution may not see many benefits at adopting this model. From the students' perspective, they may feel they might as well apply for the US program directly instead of going through the trouble of getting admitted by a Chinese institution first and applying for the US program.

While the 2nd model mandates students to meet the US requirements 100 percent, the $3^{\text {rd }}$ model - US degree with focus on major only, presents the other extreme. In the 3rd model, the US institution focuses on the major subject requirements assuming general education and correlated courses requirements are fulfilled by the courses the students take in China. The Chinese students spend X years in their home campus studying subjects the Chinese institution believes relevant and courses that will prepare them for their US study. After X years in China, students apply for the US program. If they are granted visas, they come to the US institution for Y years to study the major subjects. Upon graduation, they receive US degrees. If they are denied visas, they stay at their home institution to finish the program. They receive a Chinese degree at the end. For students who receive US degrees, the English language skills can be achieved by the fact that the students live in the native language environment, they interact with native speakers, and they take major required and elective courses. The students do have to fulfill all major requirements in order to graduate.

What is appealing in this approach is the Chinese university does not have to make many adjustments in its curriculum design, and even if visa or cost forbids them to travel abroad, the Chinese students will receive a degree at the end as long as they share their part in studying. However, this approach presents a challenge to the US institutions. Unless they are very small and private schools, US universities most likely will have difficulty going 
through all the channels to convince administrators and faculty that this type of special arrangements can be made for students who come from their partner schools in China.

The $4^{\text {th }}$ model - US degree with combination of US and Chinese requirements, is another alternative. The relationship between the Chinese and the US universities in this case is similar to the one between a community college and a four year college. Through negotiation and careful study of course content, there are agreements between the US and the Chinese universities regarding what courses can be directly transferred, what courses can be partially transferred, what US courses can be substituted by Chinese courses. As long as students are given solid advice and are careful in picking courses, they are expected to finish their US university requirements, general education requirements, correlated courses requirements, and some introductory major courses during their stay in China and they come to the US only for their language skills and major courses.

In this model both universities are active participants of the joint program. The cost burden on the students is reduced since much preparation can be done in China. There are no risks of not getting any degree at the end in case the visa or finance issue arises. In order to make this model work, hard work and flexibility is needed on the part of the universities. Adopting political theory courses such as Dengxiaoping Theory, Maozedong Theory etc to fit into the social sciences requirements requires flexibility. Deciding transfer courses requires effort by the faculties of each University. To make the model a success, the US University needs to be open minded on some Chinese courses to determine the best fit for the Chinese course. Decision on transfer courses requires evaluation of syllabus and most likely onsite visit to ensure same content is covered and quality is not compromised. A solid job in this model can easily lead to the opportunity of a dual degree program where a student receives a Chinese degree and a US degree without much duplicated effort.

University of Indianapolis (UIndy) and Ningbo Institute of Technology (NIT) developed a 2 plus 2 joint program in business and English [6]. The students study at NIT for two years and then spend the last two years at UIndy. If students fail to get visa, courses are offered by UIndy professors at NIT. Upon graduation, students receive degrees from both NIT and UIndy regardless of where the students spend the last two years. Shorter College has a similar program with Huanghe Science and
Technology University [4]. Students receive dual degrees upon graduation. It is unknown, though, how exactly these programs are implemented. Several inquiries were sent and more information will be shared when it becomes known.

\section{CONCLUSION}

A joint program brings many rewards, but at the same time presents numerous curriculum challenges which several program models can be designed to resolve. The Chinese degree model is the easiest to implement while the model of US degree with combination of US and Chinese requirements is the most beneficial to the students but requires the most cooperation of the schools in both countries.

Besides the curriculum challenges, it is necessary to keep in mind that a joint program with China needs approval from the Ministry of Education in China, which tends to favor certain subject areas depending on the needs of the country at that time. English language programs were popular in the Seventies, science and technology was in high demand in the 80 s and 90s, and management science has become the most desirable in the last ten years [14]. There are 52 approved joint bachelor degree programs [5], the majority of which are in the areas of management and technology with English speaking countries such as Britain, Australia, and US. Sources also indicate that the degree which combines technology and business, such as information systems management, will be highly desirable. Nursing is another area in which the Chinese need additional expertise from western countries, especially US.

On the US side, some US degree programs have external accrediting agencies; most notably is the AACSB accrediting agency for School of Business programs. In order to establish a joint degree program with an AACSB Accredited School of Business accreditation issues need to be addressed.

Our school is looking into two programs currently: business with technology management and nursing. Several faculty and university administrators will visit China in summer. Findings from the trip will be reported in the conference.

\section{REFERENCES}

1. Bereday, G. (1964) Comparative Method in Education, New York, Holt, Rinehart, and Winston.

2. ED.06/GATS Seminar.Asia-Pacific/1 pg. 56

3. GLOBALIZATION101 (2007)

www.globalization101.org/What_is_Globalizatio 
n.html?PHPSESSID=6461e1f581fcbe8f757f4da 2439607f6 LDOA 2/23/07

4. HHSTU (2007) www.hhstu.edu.cn/zi/jianjie.htm Chinese language LDOA 2/23/07

5. JSJ (2007) www.jsj.edu.cn/he/info_list.php?s=7 Chinese language LDOA 2/23/07

6. NIT (2007) www.nit.net.cn/internation_ban.htm Chinese language LDOA 2/23/07

7. NUST (2005) Nanjin University of Science and Technology Catalog 2005 (Chinese Language)

8. SUES (2007) www.sues.edu.cn/gjjlc/ShowArticle.asp?ArticleI $\mathrm{D}=301$ Chinese language LDOA 2/23/07

9. SUST (2005) Shanghai University of Science and Technology Catalog 2005 (Chinese Language)

10. The Lisbon/ UNESCO

11. WU (2007) Washburn University Catalog 2007

12. WISC (2007) www.ls.wisc.edu/gened/ LDOA $2 / 23 / 07$

13. ZNU (2005) Zhejiang Normal University Catalog 2005 (Chinese Language)

14. Zhang, C. (2003) Transnational Higher Education in China: Why Has the State Encouraged its Development?, School of Education, Stanford University 